\title{
Biomass burning history in East Asia during the last 4 million years recorded in elemental carbon variability at IODP site U1423
}

\author{
Song Lu ${ }^{1 *}\left(\mathbb{B}\right.$, Tomohisa Irino ${ }^{2}$ and Yaeko Igarashi ${ }^{3}$
}

\begin{abstract}
The burning of trees and grasses produces charred particles, such as charcoal and soot, that can be transported over long distances via winds and rivers to coastal, deltaic, and ocean environments, where they are preserved in sediments. Charcoal contained in sediments has been widely used as a proxy for biomass burning and human activities as well as climate change. Charcoal and soot in Cenozoic marine sediments at Integrated Ocean Drilling Program (IODP) Expedition (Exp.) 346 Site U1423 were measured to examine the regional history of biomass burning in East Asia. Charcoal and soot were measured as elemental carbon (EC) in coarse $(>2 \mu \mathrm{m})$ and fine $(<2 \mu \mathrm{m})$ fractions using grain size separation by repeated settling followed by application of a thermal optical transmittance (TOT) method. Organic carbon (OC) was also quantified during the process. EC and $\mathrm{OC}$ in both coarse and fine fractions are higher from 0 to $1.8 \mathrm{Ma}$ and lower from 1. 8 to $4.3 \mathrm{Ma}$ but have large variations, which suggest more frequent or intense biomass burning since $1.8 \mathrm{Ma}$. Terrestrial biomass and precipitation could be major controls on the EC supply. Fine EC varies independently from coarse EC, which suggests a remote origin of fine EC. Large increases in terrestrial vegetation cover have led to high-temperature burning, which is associated with interglacial stages.
\end{abstract}

\section{Introduction}

Elemental carbon (EC) is a combustion residue defined as "combustion produced black particulate carbon having a graphitic microstructure" (Novakov 1984). Thermal optical analyses have been widely used as analytical methods that could provide reasonable estimates of EC contents in marine sediments (Buseck et al. 2014). Referring to the previous research results, EC could be defined as the high-temperature component of thermal optical analyses, whereas organic carbon $(\mathrm{OC})$ was the low-temperature component of the analyses. EC is also called soot, black carbon, charcoal, spheroidal carbonaceous particles, or charged particles (Gustafsson and Gschwend 1998; Glaser and Amelung 2003; Preston and Schmidt 2006). The chemical properties of EC are stable and have a long mean residence time in soil (Swift 2001).

\footnotetext{
* Correspondence: lusong@ees.hokudai.ac.jp

${ }^{1}$ Graduate School of Environmental Science, Hokkaido University, N10W5,

Kita-ku, Sapporo 060-0810, Japan

Full list of author information is available at the end of the article
}

EC generally originates from the residues of fossil fuel or biomass burning, and the color is dark, mostly nearly black or brown (Andreae and Gelencsér 2006). The color of EC allows them to absorb a large amount of radiation energy in the atmosphere, which has a significant impact on climate (Buseck et al. 2014; Oshima et al. 2012).

Biomass burning is related to the volume of vegetation, frequency of ignition events, and connectivity of the fuel bed (Archibald et al. 2012), where these factors could be controlled by climate change as well as human activity. Biomass may be ignited by lightning strikes, volcanic activity, sparks from rockfalls, and spontaneous combustion. A most important trigger is lightning (Batchelder 1967; Komarek Sr. 1967). Increased precipitation may limit the spreading of fires in wet environments (Bowman et al. 2011; Marlon et al. 2013). However, precipitation and charcoal content could be decreased at the same time because a precipitation decrease could cause a decrease in the frequency of ignition events, such as lightning strikes. Drought conditions 
may lead to reductions in biomass burning by decreasing vegetation volume and areal cover, breaking the connectivity of the fuel bed, and reducing the frequency of ignition events (Archibald et al. 2012). Based on the HYDE dataset, it is speculated that the human population before $12 \mathrm{ka}$ in the Asian monsoon area was less than 1 million, and human activities could not have had a large influence on fire regimes before the Holocene (Marlon et al. 2013). Therefore, natural conditions, such as climate and vegetation, were the main controlling factors of EC variability on a million year time scale.

The range of transport of macroscopic EC is limited (Peters and Higuera 2007), although coarse particles of EC may be transported out of a fire site by water (Scott 2010). On the other hand, fine EC can be transported over long distances as an aerosol (Thevenon et al. 2010). Previous studies of EC dispersion had shown that more than $90 \%$ of the EC with diameters $>2 \mu \mathrm{m}$ fell out of the atmosphere, whereas more than $80 \%$ of the EC with diameters $<2 \mu \mathrm{m}$ could remain airborne (Masiello 2004). The diameter of $2 \mu \mathrm{m}$ is critical for whether EC particles can be transported by winds. Research on modern aerosol (Han et al. 2008; Wang et al. 2012; Huang et al. 2014) and past eolian dust variability showed that the source of fine terrigenous clastic particles in the north Pacific was central and northern Eurasia, and their flux could be a proxy for the continental aridity (Irino and Tada 2003) or the length of dust season (Ono and Irino 2004). In this study, the relationship between biomass burning and vegetation (climate) changes in East Asia on a time-scale longer than $100 \mathrm{ky}$ is examined using marine sediments that are anticipated to receive biomass burning products from the East Asian monsoon region.

\section{U1423 stratigraphy and samples}

Integrated Ocean Drilling Program (IODP) Expedition (Exp.) 346 Site U1423 is located in the eastern part of the Japan Basin at $41^{\circ} 41.95^{\prime} \mathrm{N}, 139^{\circ} 4.98^{\prime} \mathrm{E}$ and was recovered from a $1785 \mathrm{~m}$ water depth (Fig. 1; Igarashi et al. 2018). Site U1423 is situated on the middle of the slope at Oshima Island and is under the direct influence of the Tsushima Warm Current (TWC). The TWC flows toward the Tsugaru Strait and the Soya Strait (Yoon and Kim 2009). Because the depth of the Soya Strait is only $55 \mathrm{~m}$, sea level changes could significantly affect the strength of the TWC, which can transport materials downstream.

The sediment cores taken from Site U1423 extend from the Holocene to the early Pliocene and are dominated by clay, silty clay, and diatom ooze. The depth scales used during the cruise were CSF-A, CCSF-A, and CCSF-D (Tada et al. 2015). CSF-A is the depth (m) drilled from the sea floor regardless of potential gaps and overlaps between cores. Because more than one hole was drilled at each site during Exp. 346, the core gaps recognized at one hole were fulfilled with the corresponding interval found at an adjacent hole, and a composite depth scale (CCSF-A) was defined by adjusting the original drilled depth (CSF-A) for each hole. Splicing continuous intervals from the multi-hole sequences, a single continuous sediment sequence was established, the depth scale of which was called CCSF-D. The sediment sequence is divided into two units based on lithology (Tada et al. 2015). Unit I (0-107 m CCSF-D) mainly consists of silty clay and clay, exhibiting cycles of dark (organic matter rich) and light (organic matter poor) colored layers. Unit II (107-240 m CCSF-D) mainly consists of diatomaceous silty clay, clay, and diatom ooze, which is homogeneous or bioturbated.

The initial stratigraphic frameworks and spliced depth scale (m CCSF-D) established onboard were mainly based on the sediments' physical properties, such as color (RGB or reflectance spectrum and colorimetry (RSC)), gamma-ray attenuation density (GRA), natural gamma-ray radiation (NGR), and magnetic susceptibility (MS). However, disturbances in the half cut core, such as Styrofoam (filled for voids and interstitial-water/ paleontological sampling intervals), core liquefaction, rotated ash layers, scratched surfaces, deformations, and drilling faults, can be only recognized by visual inspection, which may lead to noises in the profile of physical properties. Such disturbed stratigraphic intervals involved in the spliced sequence could be removed and replaced with the corresponding undisturbed intervals found in the other hole. By these amendments of the original spliced sequence, a nearly continuous sequence was established (Irino et al. 2018). The revised depth scale is defined as m CCSF-D_Patched. Using this patched stratigraphic sequence, we could establish a more accurate stratigraphic framework.

Because the resolution of the initial age model is not high and one of the control points is ambiguous (Tada et al. 2015), the age model for U1423 was also revised. U1424 is located at the southeastern margin of the Japan Basin at $40^{\circ} 11.40^{\prime} \mathrm{N}, 138^{\circ} 13.90^{\prime} \mathrm{E}$ (Tada et al. 2015) and is close to Site U1423. Both sites are under the influence of the first branch of the TWC. At Site U1424, GRA and NGR were tuned onto the LR04 benthic isotope stratigraphy (Lisiecki and Raymo 2005) by Tada et al. (2018). We projected this "U1424_LR04 tuned age" to Site U1423 based on the inter-site correlation using dark-light cycles (Tada et al. 2018) from 0 to $75 \mathrm{~m}$ CCSF-D_Patched. From 75 to 127 m CCSF-D_Patched, the GRA density of Site U1423 was directly tuned onto the LR04 oxygen isotope stratigraphy (Fig. 2; Lisiecki and Raymo 2005). We used a total of 200 control points to maintain a high-resolution age model for the last 3 Myr, and the control points are shown in Figs. 2 and 3 


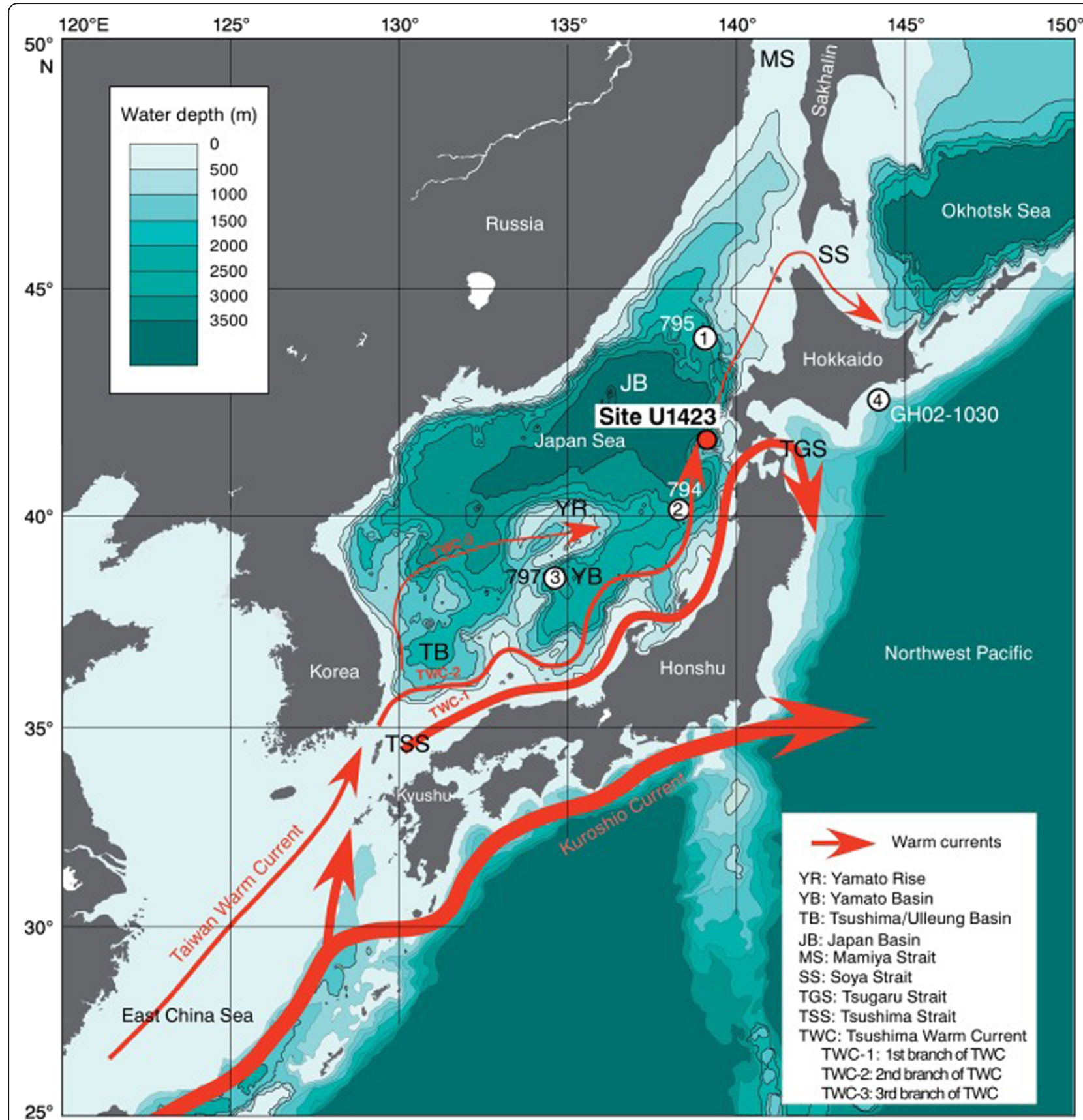

Fig. 1 Map showing the studied sea area and location of Site U1423. The locations of (1) Site 795, (2) Site 794, and (3) Site 797 in Heusser (1992) and (4) Site GH02-1030 in Igarashi et al. (2011) are also shown (from Igarashi et al. 2018)

and listed in Additional file 1: Table S1. GRA at U1423 could be regarded as a proxy for sea level change in the Japan Sea because a low GRA associated with high diatom content indicates high sea level (Tada et al. 1999). Below 146.7 m CCSF-D_Patched, age control points adopted in the cruise report were used (Fig. 3; Tada et al. 2015). The 109 samples between 0 and $200 \mathrm{~m}$ CCSF-D_Patched were collected for this study, which covered the last 4.3 Myr.

\section{Analytical methods}

\section{Sample preparation}

Sediments were freeze-dried, after which $100 \mathrm{mg}$ of each sample were treated with $1.2 \mathrm{~N}$ hydrochloric acid at room temperature overnight to remove carbonate and rinsed with milli- $Q$ water twice to remove salts. The samples were dispersed in milli- $\mathrm{Q}$ water and separated into $<2 \mu \mathrm{m}$ (fine fraction) and $>2 \mu \mathrm{m}$ (coarse fraction) by the repeated settling method (Folk 1980). The fine 

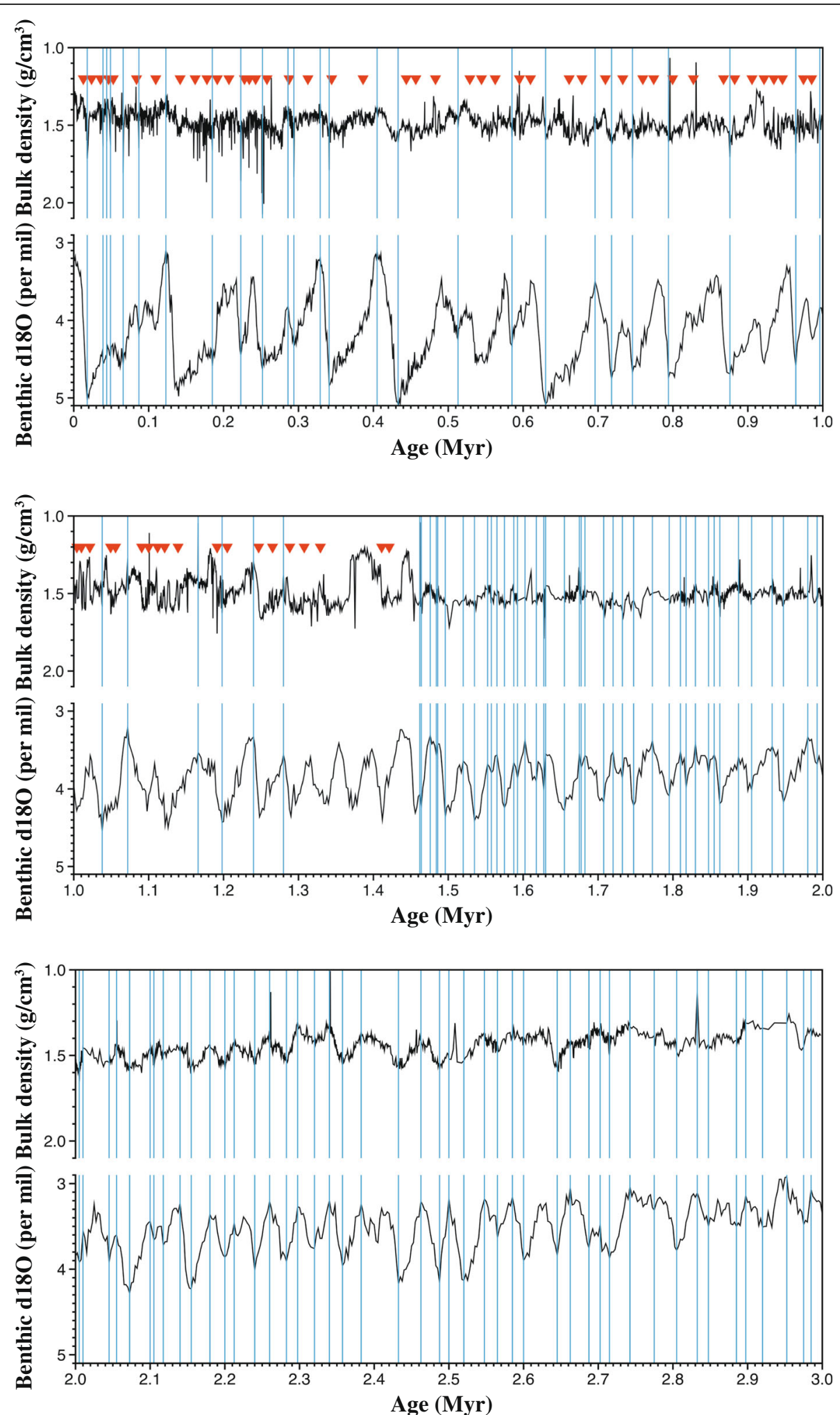

Fig. 2 Revised age model for U1423 based on projection of the "U1424_LR04 tuned age" (Tada et al. 2018) to site U1423 by the inter-site correlation of dark-light cycles for the last $1.5 \mathrm{Ma}$ (red inverted triangles) and tuning of the GRA profile to the LR04 stack (vertical lines). Assuming that a high GRA represents glacial maxima, 118 horizons have been correlated to maxima of the oxygen isotope profile of LR04 for the last 2.975 Myr 


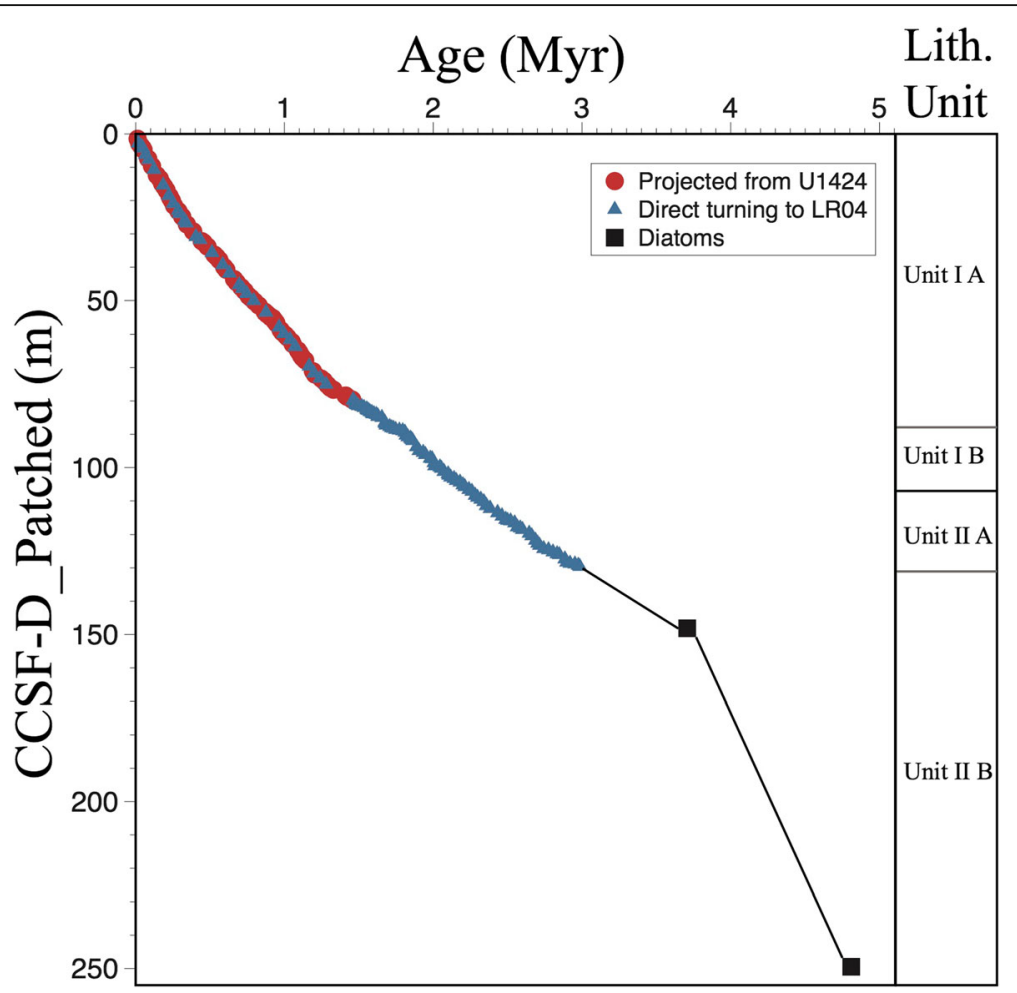

Fig. 3 The age-depth relationship of the revised age model for site U1423 used in this study. The age control points from the Expedition Report (Tada et al. 2015) is also indicated by the black dots and lines

fractions were collected on $\Phi 49 \mathrm{~mm}$ quartz fiber filters using suction filtration, while the coarse fractions were collected by centrifugation at $3000 \mathrm{rpm}$ for $30 \mathrm{~min}$ followed by freeze drying and weighing.

\section{Thermal optical transmittance analysis}

The analysis was conducted using a Semi-Continuous OCEC Carbon Aerosol Analyzer manufactured by Sunset Laboratory (Miyazaki et al. 2007) at the Institute of Low Temperature Science, Hokkaido University. This apparatus is equipped with a thermal optical transmittance (TOT) system that uses a highly sensitive analytical method for determining the content of EC. The contents of EC in both fine and coarse fractions of Site U1423 samples were measured as a proxy for biomass burning. For the fine fraction, a $\Phi 14 \mathrm{~mm}$ part was punched out from the $\Phi 49 \mathrm{~mm}$ quartz fiber filter and covered with another blank $\Phi 14 \mathrm{~mm}$ quartz fiber filter. For the coarse fraction, a known amount (approximately $10 \mathrm{mg}$ ) of the freeze dried fraction was sandwiched by two $\Phi 14 \mathrm{~mm}$ quartz fiber filters. These prepared $\Phi 14 \mathrm{~mm}$ quartz fiber filters were set in the quartz glass tube of the apparatus.

In this study, we used a temperature protocol based on that proposed by the Institute of Low Temperature Science (Miyazaki et al. 2007). A single sample was placed immediately into the apparatus. Figure 4a shows an example thermogram used in this study. The combustion temperature was increased from room temperature to a high temperature in five steps $\left(250{ }^{\circ} \mathrm{C}\right.$, $350{ }^{\circ} \mathrm{C}, 550{ }^{\circ} \mathrm{C}, 750{ }^{\circ} \mathrm{C}$, and $850{ }^{\circ} \mathrm{C}$ ). The duration of each temperature step and heating rate were set as constants and routinely controlled by a computer program. The ambient environment was a complete helium atmosphere from 0 to $370 \mathrm{~s}$ at three temperature steps $\left(250^{\circ}, 350^{\circ}\right.$, and $\left.550{ }^{\circ} \mathrm{C}\right)$ to remove non-fire-resistant organic carbon $(\mathrm{OC})$, and, then, from 371 to $820 \mathrm{~s}$, the atmosphere was switched to a $2 \%$ oxygen/helium mixture at temperature steps of $550{ }^{\circ} \mathrm{C}, 750{ }^{\circ} \mathrm{C}$, and $850{ }^{\circ} \mathrm{C}$ to combust the residual carbon. Carbon fractions extracted at each temperature step were detected and quantified by a non-dispersive infrared (NDIR) sensor and defined as six carbon fractions from $\mathrm{C} 1$ to $\mathrm{C} 6$ (Fig. 4a). From 821 s, a fixed volume of methane was injected into the quartz tube, providing a known quantity of carbon. The carbon amount of the introduced methane was calibrated using sucrose standards before measurement.

During the entire combustion sequence above, laser transmission was also monitored to determine how the blackness of the sample filter changed (Fig. 4a). The laser transmission data generated by the apparatus were necessary to calibrate for its temperature dependency and convert the value to a "transmission ratio," where 


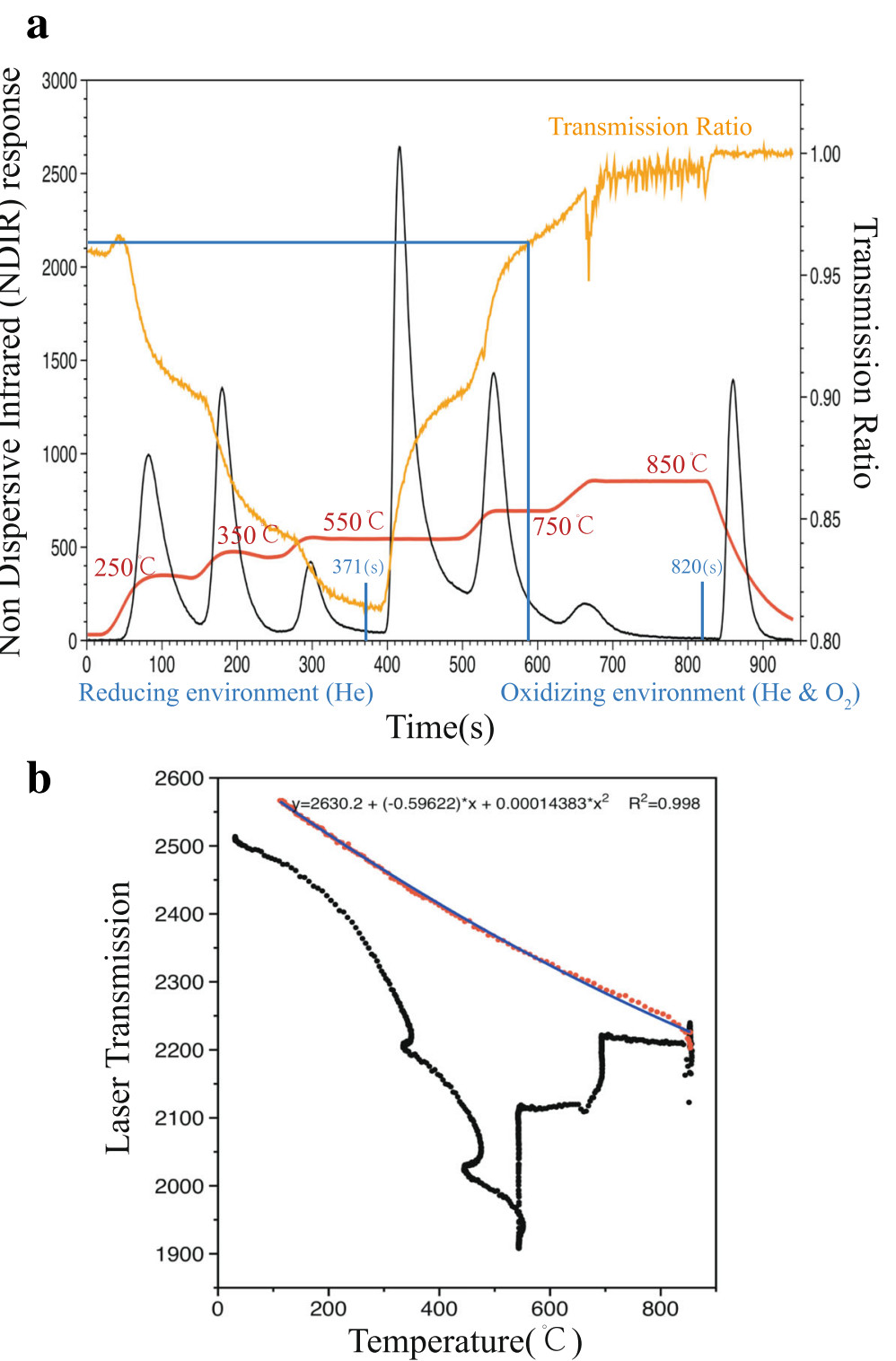

Fig. 4 a An example thermal optical transmittance (TOT) thermogram. Temperature change is represented as red line, and the corrected laser transmission ratio is represented by orange line. The carbon fraction detected by NDIR response is represented as black line. $\mathbf{b}$ The relationship between the ambient temperature and the original laser transmission generated by a Semi-Continuous OCEC Carbon Aerosol Analyzer manufactured by Sunset Laboratory. The temperature dependency of the raw laser transmission values was calibrated using a quadratic relationship, with the ambient temperatures shown as red dots

the laser transmission with no carbon fraction (after the measurement sequence) was set to unity (Fig. 4a). The relationship between the laser transmission and temperature can be expressed as a quadratic function (Fig. 4b; red dots), where all the "black" carbon materials had been removed. The quadratic function could provide the laser transmission value anticipated at a temperature with no "black" carbon in the sample. The laser transmission at each temperature during the measurement was divided by this anticipated laser transmission value, which yielded the "transmission ratio." Under the helium atmosphere, part of the carbon was charred, the sample became darker, and the laser transmission ratio decreased. Then, under an oxygen atmosphere, charred carbon was burned, and the laser transmission ratio was recovered to the original level. We defined the carbon generated from $0 \mathrm{~s}$ to this time as $\mathrm{OC}$, and the carbon extracted between the time when the laser transmission was recovered to the original level and $820 \mathrm{~s}$ was regarded as EC (Fig. 4a).

Analytical errors were introduced during the determination of carbon amount and the distinction of $\mathrm{OC}$ 
and EC. The uncertainty during carbon determination was $\pm 1.8 \mu \mathrm{gC}$ for a single measurement, whereas the error related to distinguishing OC-EC was $\pm 0.4 \mu \mathrm{gC}$ due to the uncertainty of the initial laser transmission. Depending on the sample amount $(\sim 10 \mathrm{mg}$ and 10 $30 \mathrm{mg}$ for coarse and fine fractions, respectively) collected on the quartz fiber filter, the total EC determination errors were $\pm 0.22 \mathrm{mgC} / \mathrm{g}$ sediment for the coarse fraction and $\pm 0.7 \mathrm{mgC} / \mathrm{g}$ sediment for the fine fraction.

\section{Results}

The contents of OC and EC during the last 4.3 Myr at Site U1423 are shown in Fig. 5a, b, respectively. The contents of OC and EC are high in subunit IA (0$1.8 \mathrm{Ma})$ and decrease rapidly downward in the upper part of subunit IB (1.8-2.2 Ma), and low levels are maintained in aubunits IIA (2.2-3.0 Ma) and IIB $(>3.0 \mathrm{Ma})$. $\mathrm{OC}$ and EC in the coarse $(>2 \mu \mathrm{m})$ fraction are $5-10$ times higher than those in the fine $(<2 \mu \mathrm{m})$ fraction. The OC content is much higher than the EC content of the coarse fraction, whereas the $\mathrm{EC}$ content of the fine fraction is occasionally much higher than the OC content. The content of coarse EC is steady in subunit IIB ( $>3.0 \mathrm{Ma}$ ), whereas the content of fine EC shows significant fluctuations in the same subunit.
To compare the data showing different absolute values and dynamic ranges, conversions of raw data into standard scores (Z-score) were conducted and are shown in Fig. 5c. Photo RGB-B can be used as a proxy for sediment brightness, which is also shown in Fig. 5c. In general, the contents of coarse OC and EC are high in the dark layers and low in the light layers for all the lithological units. The high OC contents in the fine fraction are not necessarily associated with low sediment brightness.

\section{Discussion}

\section{Sediment brightness and carbon content}

The general tendency that high coarse OC and EC are associated with darker color layers (Fig. 5c) suggests a significant effect of OC-EC supply to the dark layer formation in spite of a potential influence of carbonate fraction on the sediment brightness. However, the sediment at Site U1423 had only a small amount of calcium carbonate content ranging from 0.2 to $1.0 \mathrm{wt} \%$ (average $0.4 \mathrm{wt} \%$; Tada et al. 2015), and the high calcium carbonate contents were exceptional and restricted only in several layers rich in foraminifers, whose calcium carbonate contents were up to $14 \mathrm{wt} \%$. Therefore, the calcium carbonate at this site could have a weak effect

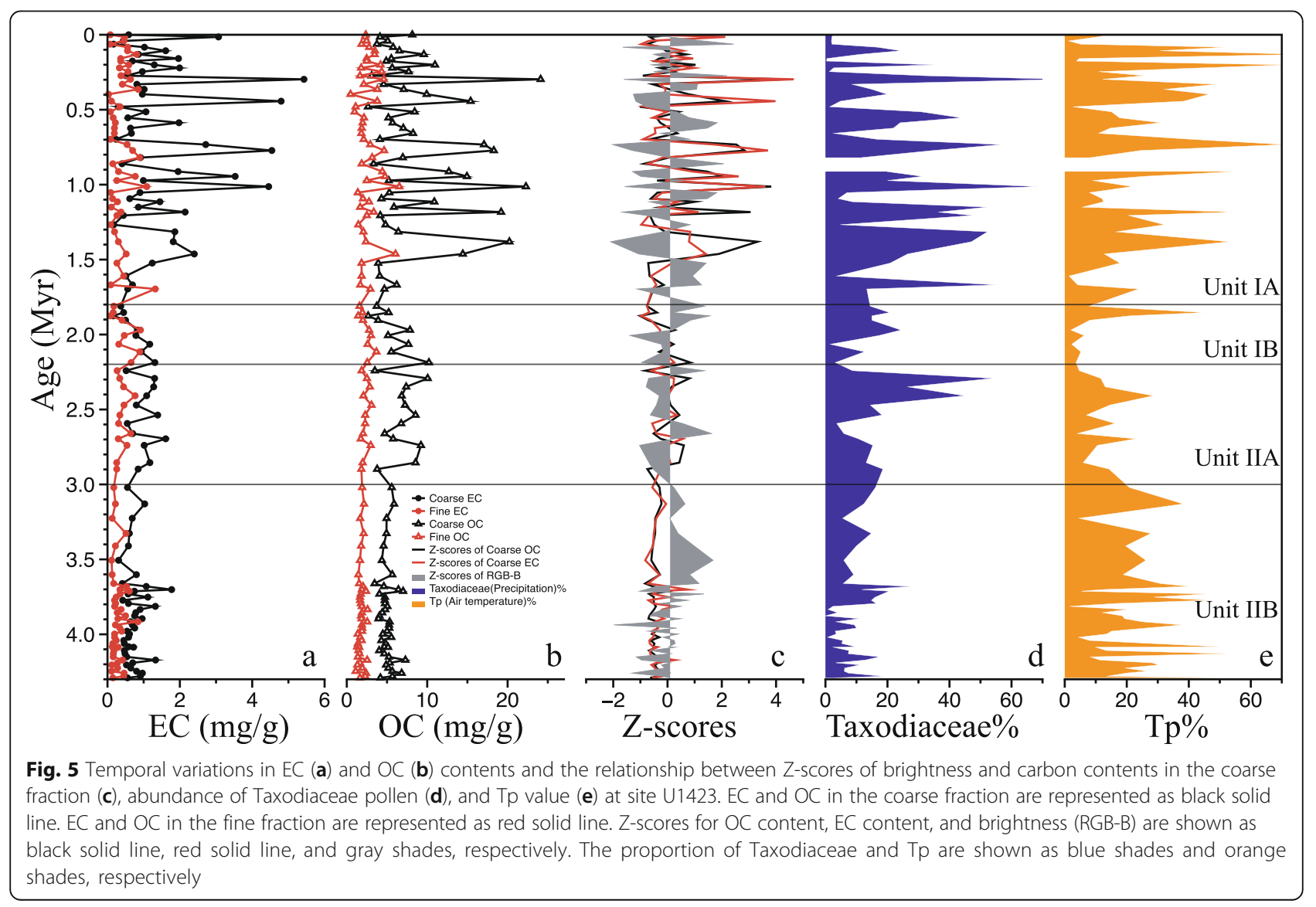


on the brightness of sediments, whereas the OC and EC contents in the coarse fraction could be major controlling factors of sediment brightness.

Previous reports have also shown that the high organic matter contents in the sediments of the Japan Sea were correlated to the dark layers that were deposited during interstadials due to stronger summer monsoon precipitation (Tada et al. 1999). Research on fire-regime indicates that the EC content is controlled by fire intensity, which could be related to climate as well as fuel type and load (terrestrial vegetation; Iglesias and Whitlock2014), and coarse EC particles $(>2 \mu \mathrm{m})$, such as charcoals, are usually an important part of river suspended solids (C. A. Masiello and Druffel 2001; Schmidt et al. 2002). The dark layers at Site U1423 also contain higher coarse EC as well as OC, while the light layers contain lower amounts. This observation suggested that coarse EC was generated by more frequent paleofires in northern Japan and transported by river during interstadials rather than during stadials. During the interstadials, higher summer precipitation could have promoted a larger terrestrial biomass in northern Japan, and the large amounts of fuel load were consumed, which produced rich EC.

\section{Pollen assemblage and carbon contents}

The pollen assemblage could reveal more information on vegetation and climate. Here, we compared our EC analysis results with pollen assemblage data collected from the same sample set (Igarashi et al. 2018). To understand the relationship between OC/ EC supply to Site U1423 and paleoclimate, we examine the proportion of broadleaf (Tw) and the sum of broadleaf (Tw) and conifer (Tc), which is defined as $\mathrm{Tp} \%(=[\mathrm{Tw} /(\mathrm{Tw}+\mathrm{Tc})] \times 100) ;$ Fig. $5 \mathrm{e}) . \mathrm{Tp}$ was regarded as a proxy of air temperature, while Taxodiaceae\% was considered to be a precipitation proxy (Igarashi et al. 2018; Fig. 5d). Using these two pollen proxies, we classified climatic regime into four categories, which were cool-dry, cool-wet, warm-dry, and warm-wet. The threshold used to distinguish the cool and warm categories was set to a median value of $\mathrm{Tp} \%$, whereas that for the cool and warm categories was set to the median value of Taxodiaceae\%. Because each sample was attributed to its own climate category, we calculated the average $\mathrm{OC}$ and EC contents for each climate category shown in Table 1 . Coarse OC was higher during warm climates than in cool climates, regardless of dry/wet conditions. The content of fine OC/EC was not sensitive to any of the climate categories. On the other hand, coarse EC shows higher values under a wet condition than under a dry condition, although there was no significant difference between cool and warm conditions.
Table 1 The averages of OC and EC contents for the four climatic categories

\begin{tabular}{lcc}
\hline & Dry & Wet \\
\hline Coarse OC $(\mathrm{mg} / \mathrm{g})$ & 5.6 & 5.5 \\
Cool & 7.5 & 8.7 \\
Warm & & \\
Coarse EC $(\mathrm{mg} / \mathrm{g})$ & 0.8 & 1.2 \\
Cool & 0.9 & 1.4 \\
Warm & & \\
Fine OC $(\mathrm{mg} / \mathrm{g})$ & 2.1 & 2.5 \\
Cool & 1.9 & 2.7 \\
Warm & & \\
Fine EC (mg/g) & 0.3 & 0.4 \\
Cool & 0.3 & 0.4 \\
Warm & & \\
\hline
\end{tabular}

This suggests that precipitation might be a potential control on coarse EC supplied to Site U1423.

The total pollen number was a proxy for the volume of terrestrial vegetation that could be a major part of biomass fuel load for fires. The relationship between pollen count and coarse EC content shows a weak positive correlation $\left(R^{2}=0.417, p<0.001\right.$; Fig.6), with an exceptional outlier with high pollen number $(92,022 / \mathrm{g})$ and low coarse EC $(0.689 \mathrm{mg} / \mathrm{g})$. Despite the weak positive correlation between them, a larger biomass or high biomass fuel load could be a first-order control on coarse EC supply. The relationship between total number of pollen and fine EC content shows no significant correlation (not shown).

The Taxodiaceae\% is a proxy for humid climate (Igarashi et al. 2018). Figure 5d shows that Taxodiaceae\% shows rapid and intense changes in unit I (0-2.2 Ma) but becomes flat in unit II $(>2.2 \mathrm{Ma})$, which is consistent with the variabilities of coarse EC (Fig. 5a) and sediment brightness (RGB-B) (Fig. 5c). Coarse EC also shows a weak positive correlation with Taxodiaceae\% $\left(R^{2}=0.230, p<0.001\right.$; Fig. 7$)$, which suggests that heavy rain after a wildfire could also carry abundant EC to the sea through the rivers (Scott 2010). In the case of high coarse EC associated with low precipitation (Taxodiaceae\%; Fig. 7), a time lag between EC generation and transport might be responsible. Based on a study of potential charcoal source areas, the coarse EC comes from local fires (Peters and Higuera 2007), and soils act as an intermediate stage for the aging of EC prior to deposition in the ocean (Schmidt et al. 2002).

\section{Factors controlling EC grain size}

Fine EC content varies independently from coarse EC content (Fig. 5a), which suggests a remote origin of fine EC. The fine particles of EC might be transported out of 


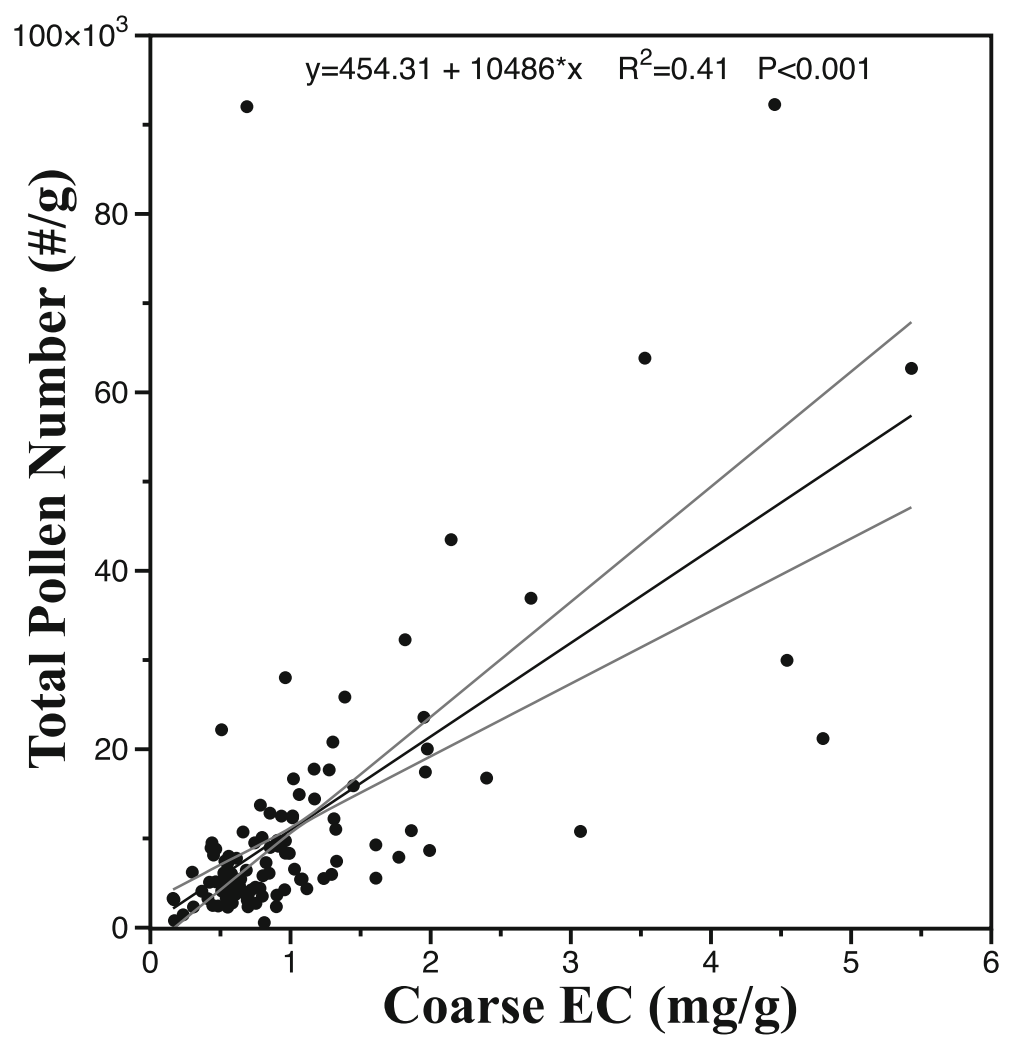

Fig. 6 Relationship between pollen content and EC content in the coarse fraction at site U1423. The gray lines represent the 95\% of confidence interval envelopes

a fire site by wind, which is different from coarse EC (Scott 2010). In particular, canopy fires can produce fine EC particles that are susceptible to wind dispersal. Taking into account the fact that the fine particles could be transported over long distances as aerosols, unusually high contents of fine EC suggest contributions from remote fires. Wildfires occur mainly in spring and autumn in East Asia because fires are mostly triggered by a sudden change in environment. Usually autumn and late winter or early spring experience numerous wildfires. Therefore, fine EC and Asian Dust could have similar transport processes. Based on modern aerosol research (Huang et al. 2014) and high-resolution variations in eolian dust research (Irino and Tada 2003), eastern and northwest China and Mongolia could be sources of fine EC. Strong westerly winds can carry large amounts of fine particulate matter over long distances and could finally deposit them in the Japan Sea.

Our high-resolution age model covers the last 3 Myr, which enables us to examine the relationship between EC grain size and glacial-interglacial cycles. Six maxima events in fine EC/coarse EC occurred during interglacial (low GRA) intervals (Fig. 8). In interglacial stages, large-scale terrestrial vegetation could provide ample loads of fuel and higher chances for ignition events, where lightning might be a main ignition event (Marlon et al. 2013). These conditions could provide the possibility of large-scale biomass burning, which could generate fine elemental carbon in East Asia. We note that the high interglacial precipitation was not sufficiently powerful to drive a linear change in local fires (Fig. 6), and their correlation was weak. When precipitation exceeded a threshold, it may suppressed or promoted fires. However, it is difficult to quantify this threshold simply by relying on current pollen data. Such large-scale biomass burning at a remote fire site could have served as a fine EC supply for Site U1423.

A set of second-highest peaks of Fine EC/Coarse EC appeared in the glacial stages, which were found during 267 279 ka and 358 370 ka (Fig. 8). Lower peaks also appeared in the glacial stages, which were found during 1.60 1.63 Ma and 2.11 2.13 Ma (Fig. 8). Under normal circumstances, the amount of coarse EC is much higher than that for fine EC. Changes in wind strength could significantly affect fine EC flux. Therefore, these exceptionally high fine EC contents suggest a special condition of enhanced winds during particular glacial stages, which corresponded to MIS 8, MIS 10, MIS 56, and MIS 80. 


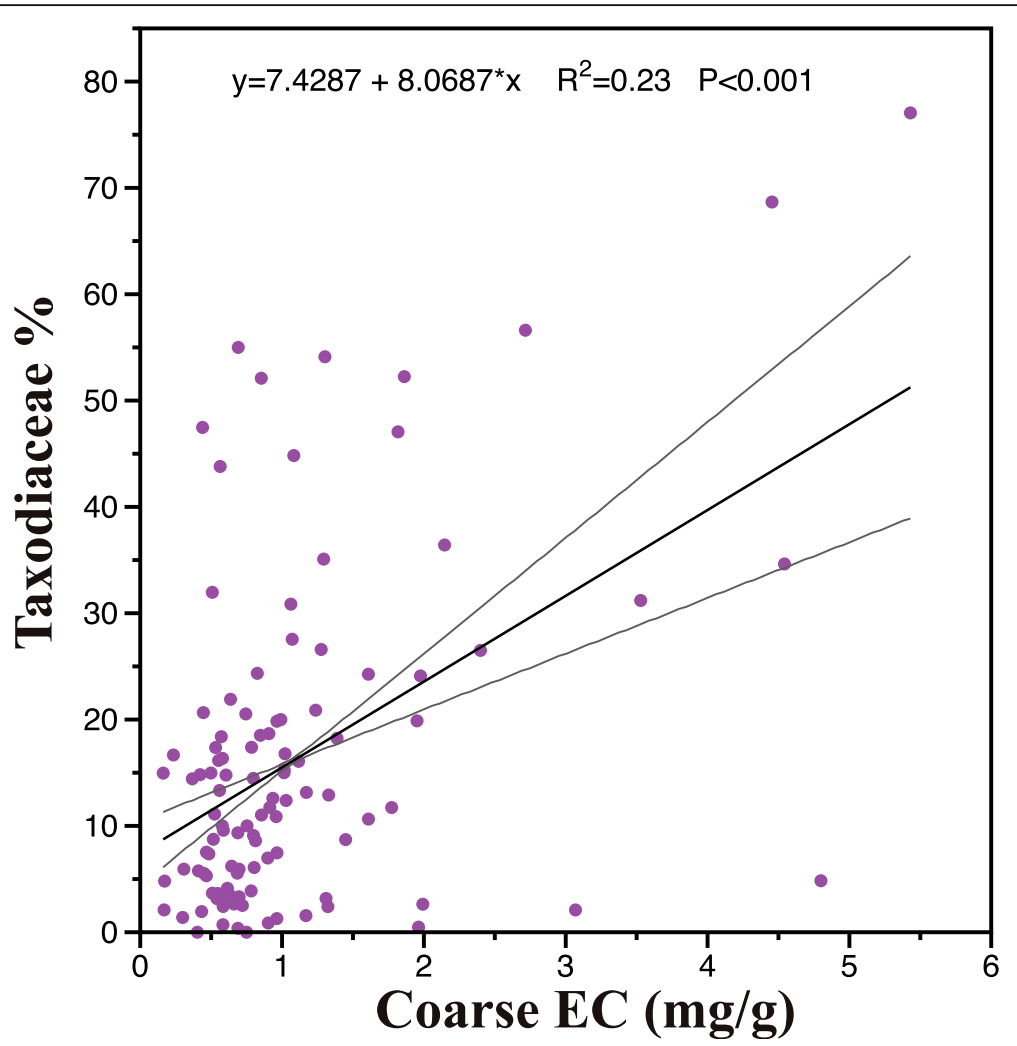

Fig. 7 Relationship between Taxodiaceae and EC content in the coarse fraction at site U1423. The gray lines represent the 95\% of confidence interval envelopes

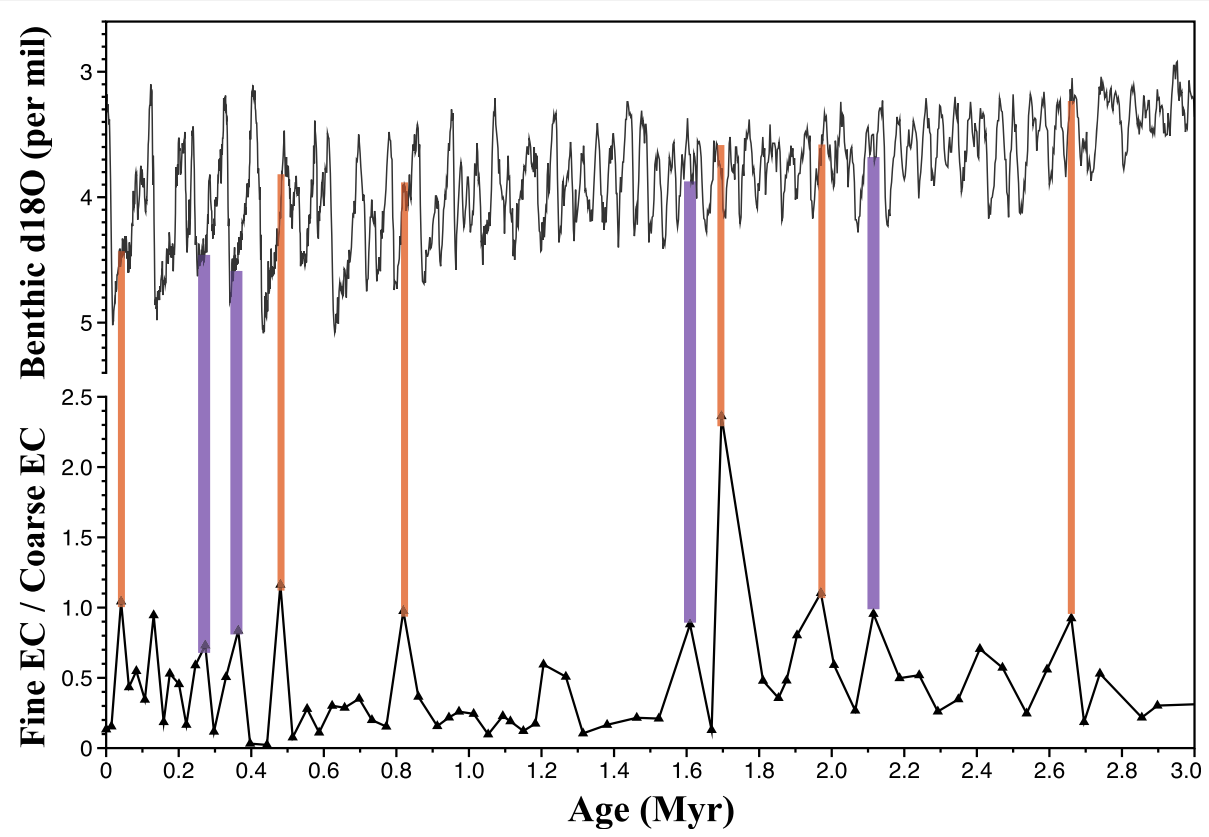

Fig. 8 Temporal variation of fine EC/course EC and LR04 standard benthic $\delta^{18} \mathrm{O}$ (Lisiecki and Raymo 2005. Significant maxima observed in temporal variations of fine $\mathrm{EC} /$ coarse $\mathrm{EC}$ are marked as blue and red vertical lines that correspond to glacial and interglacial stages, respectively 
The strong winds during glacial stages could carry great amounts of terrigenous clastic particles, which could cause abnormal increases in the contents of certain terrestrial substances, such as freshwater diatoms (Pokras and Mix 1987; Verardo and Ruddiman 1996). During the glacial period, the surface of mainland China was heavily weathered, and a large number of debris particles were formed. Under the influence of strong winds, this newborn terrigenous clastic debris could have been transported into the ocean. The wind strength or direction during glacial stages could also affect the change in tempo of charcoal deposition (Verardo and Ruddiman 1996). The biomass burning was relatively stable on the loess plateau (Zhou et al. 2007) for MIS 8 and MIS 10. Coarse particle content increased significantly on the loess plateau at MIS 8 and MIS 10 (Sun et al. 2003), and, at the same time, the mean grain size of bulk sample data also indicates a stronger East Asian winter monsoon (Sun et al. 2006). Based on particle sizes and the magnetic susceptibility of the Loess Plateau, weaker summer and stronger winter monsoons were suggested during MIS 8 and MIS 10 (Wang 2003; Hao et al. 2012). At MIS 56 and MIS 80, the magnetic susceptibility of the Loess Plateau shows a slightly stronger winter monsoon (Nie et al. 2008). Although the fine EC concentration increased during those particular glacial phases, it does not necessarily mean that the biomass burning or fuel load had increased. The strong winds could have carried land-deposited EC particles into the ocean.
Benefitting from the strong winter monsoon in the surrounding area, larger supplies of fine EC to Site U1423 could have been realized during MIS 8, MIS 10, MIS 56, and MIS 80.

\section{Paleoenvironment and high-temperature paleofires}

Based on the principle of the TOT method, the ratio between the sixth carbon fraction (C6) and the total elemental carbon (EC) could be an index of the high-temperature component of EC. The sixth carbon fraction (C6) is a refractory component of EC, and its formation conditions could be those of high-temperature combustion. When this index increases, the biomass burning temperature could be higher. Ordinary temperatures in biomass burning are approximately $400{ }^{\circ} \mathrm{C}$, whereas canopy fires can be much hotter (more than $800^{\circ}$ C; Scott 2010). Our high-resolution age model for U1423 covers the last $3 \mathrm{Myr}$, and we can also examine the relationship between the $\mathrm{C6} / \mathrm{EC}$ variability and glacial-interglacial cycles (Fig. 9).

Local high-temperature paleofires suggested by coarse EC were more frequent than remote high-temperature paleofires suggested by fine EC (Fig. 9). One maximum of $\mathrm{C6} / \mathrm{EC}$ in both coarse and fine fractions appeared in the glacial stage, which was found during 57 68 ka (Fig. 9; blue vertical line). Remote high-temperature paleofire maxima of fine C6/ EC also occurred at approximately $548 \sim 560 \mathrm{ka}$, 1.0 Ma, and 1.7 Ma in glacial stages (Fig. 9; blue

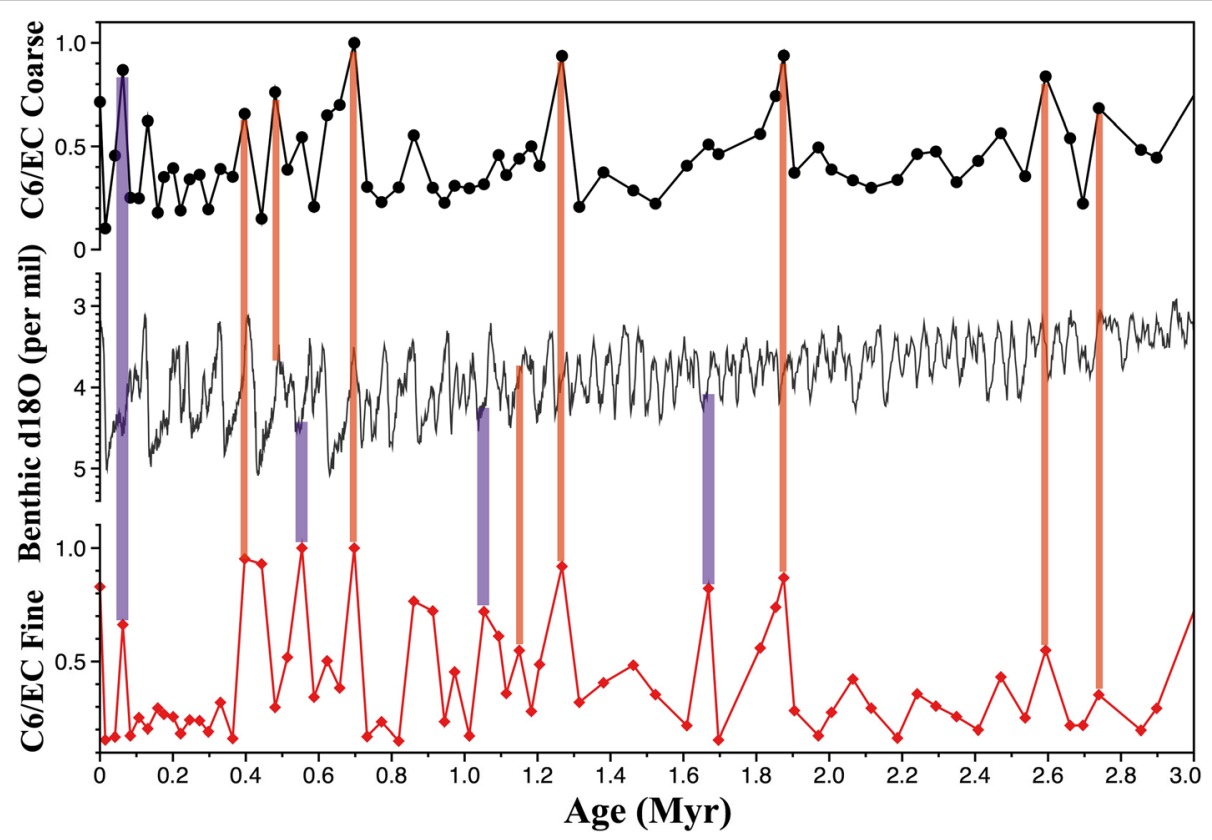

Fig. 9 LR04 standard benthic $\delta^{18} \mathrm{O}$ (Lisiecki and Raymo 2005) and C6/EC in fine and coarse fractions. The significant maxima observed in the higher temperature biomass burning proxy (C6/EC) in coarse and fine fractions are marked as blue and red vertical lines corresponding to glacial and interglacial stages, respectively 
vertical lines). In most cases, however, maxima of C6/ $\mathrm{EC}$ in coarse and fine fractions have very similar trends, and they mostly occurred in the interglacial stages (Fig. 9; red vertical lines).

These facts suggest that local high-temperature paleofires occurred more frequently during interglacial stages in northern Japan. Remote high-temperature paleofires also exhibited an enhanced trend during interglacial stages, and some glacial stages also show the signal of remote high-temperature burning. However, burning at high temperatures is difficult in a cold and dry environment. The sizes of biomass fuel loads during glacial times might have been very small and were insufficient for large-scale biomass burning or high-temperature burning. Therefore, apparent increases in remote high-temperature burning might be attributed to the fact that the winter monsoon carried the old (interglacial) high-temperature EC particles.

\section{Conclusions}

During the last 4.2 million years, coarse EC were enriched in interglacial stages or interstadials with stronger East Asian summer monsoons, suggesting that the volume of terrestrial plants affected fire intensity. Larger biomasses or high biomass fuel loads in northern Japan were dominant controls on coarse EC content. Therefore, a wet climate was preferable for coarse EC supplies to IODP Site U1423. The intensity of a local fire also depends on the local fuel load, which contains not only newborn vegetation but also dead but not decomposed vegetation. This means that the local fuel loads could have been high at the beginning of the glacial stages, which would have led to exceptionally high concentrations of coarse EC during glacial stages with apparent low terrestrial biomass.

The independent behavior of fine EC from that of coarse EC suggests its remote origin. Considerable amounts of biomass burning in the remote source area during interglacial stages or the wind strength or direction preferable for fine EC emissions from East Asia during glacial stages could have caused unusually high fine EC/coarse EC. Although remote fires were suppressed during the glacial stage, high concentrations of fine EC could be expected because of the intense erosion of soils formed during the previous interglacials and wind transport.

The high-temperature component of coarse and fine EC could be associated with interglacial stages due to preferable burning conditions, with some exceptions. Exceptional maxima of the high-temperature component of fine EC might also be attributed to the reworking of older EC formed during the previous interglacials.

\section{Additional file}

Additional file 1: Table S1. The control points for the revised age model. (XLS 42 kb)

\section{Abbreviations \\ CCSF-D: Core composite depth; EC: Elemental carbon; GRA: Gamma-ray attenuation density; IODP: Integrated Ocean Drilling Program; MS: Magnetic susceptibility; NDIR: Non-dispersive infrared sensor; NGR: Natural gamma-ray radiation; OC: Organic carbon; RSC: Reflectance spectrum and color; TOT: Thermal optical transmittance; Tp: The pollen temperature index; Tw: The sum of broadleaf; Tc, the sum of conifer}

\section{Acknowledgements}

The research included in this paper could not been performed without the assistance and supports from Profs. Atsuko Sugimoto, Hisayuki Yoshikawa, Masanobu Yamamoto, Youhei Yamashita, Ken Sawada in Hokkaido University, Ryuji Tada in University of Tokyo, and Dr. Ken Ikehara in Geological Survey of Japan, AIST. And many thanks also go to Profs. Kimitaka Kawamura, Yuzo Miyazaki, and Ms. Eri Tachibana in Institute of Low Temperature Science, Hokkaido University for allowing us to use thermal optical transmittance (TOT) system and their instructions. We would also like to acknowledge constructive feedback provided by four anonymous reviewers as well as editor. This research was financially supported by JSPS KAKENHI Grant Number 26287130 (to Ken Sawada) and IODP Exp. 346 After Cruise Research Program, JAMSTEC. The JpGU classifies reviews and articles into the following six science sections: (1) space and planetary sciences; (2) atmospheric and hydrospheric sciences; (3) human geosciences; (4) solid earth sciences; (5) biogeosciences; or (6) interdisciplinary research.

\section{Funding}

This research was financially supported by JSPS KAKENHI Grant Number 26287130 (to Ken Sawada) and IODP Exp. 346 After Cruise Research Program, JAMSTEC.

\section{Availability of data and materials}

Please contact author for data requests.

\section{Authors' contributions}

SL and TI proposed the topic, conceived and designed the study. SL carried out the experimental study for EC and OC concentrations. TI provided the revised depth scale for U1423. The high-resolution age model for U1423 was created by SL under supervision of TI. YI provided her own pollen data and advised for the interpretation. All authors read and approved the final manuscript.

\section{Authors' information}

LU Song was a master course student at Graduate School of Environmental Science, Hokkaido University under supervision by IRINO Tomohisa. This paper is a main part of master thesis and the study at 1st year doctor course of LU Song.

\section{Competing interests}

The authors declare that they have no competing interests. All institutional and national guidelines for the care and use of laboratory animals were followed.

\section{Publisher's Note}

Springer Nature remains neutral with regard to jurisdictional claims in published maps and institutional affiliations.

\section{Author details}

${ }^{1}$ Graduate School of Environmental Science, Hokkaido University, N10W5, Kita-ku, Sapporo 060-0810, Japan. ${ }^{2}$ Faculty of Environmental Earth Science, Hokkaido University, N10W5, Kita-ku, Sapporo 060-0810, Japan. ${ }^{3}$ Institute for Paleoenvironment of Northern Regions, Koyocho 3-7-5, Kitahiroshim 061-1134, Japan. 
Received: 1 October 2017 Accepted: 15 August 2018

\section{Published online: 17 September 2018}

\section{References}

Andreae MO, Gelencsér A (2006) Black carbon or brown carbon? The nature of light-absorbing carbonaceous aerosols. Atmos Chem Phys Discuss 6(3):34193463 Retrieved (https://doi.org/10.5194/acp-6-3131-2006)

Archibald S, Staver AC, Levin SA (2012) Evolution of human-driven fire regimes in Africa. Proc Natl Acad Sci 109(3):847-852 Retrieved (http:// www.pnas.org/content/109/3/847.abstract\%5Cnhttp://www.pnas.org/ content/109/3/847.full.pdf)

Batchelder RB 1967. Spatial and temporal patterns of fire in the tropical world. Proceedings Annual (6th) Tall Timbers Fire Ecology Conference (June 1966). 6:171-207.

Bowman DMJS et al (2011) The human dimension of fire regimes on earth. J Biogeogr 38(12):2223-2236

Buseck PR, Adachi K, Gelencsér A, Tompa É, Pósfai M (2014) Ns-Soot: a materialbased term for strongly light-absorbing carbonaceous particles. Aerosol Sci Technol 48(7):777-788 Retrieved (https://doi.org/10.1080/02786826.2014. 919374)

Folk RL 1980. Petrologie of sedimentary rocks. 3, p. 15-24. Hemphll Publishing Company, Austin 170

Glaser B, Amelung W (2003) Pyrogenic carbon in native grassland soils along a climosequence in North America. Glob Biogeochem Cycles 17(2):n/a Retrieved (https://doi.org/10.1029/2002GB002019)

Gustafsson O, Gschwend PM (1998) The flux of black carbon to surface sediments on the New England continental shelf. Geochim Cosmochim Acta 62(3):465-472

Han YM et al (2008) Distribution and origin of carbonaceous aerosol over a rural High-Mountain Lake area, northern China and its transport significance. Atmos Environ 42(10):2405-2414

Hao Q et al (2012) Delayed build-up of Arctic ice sheets during 400,000-year minima in insolation variability. Nature 490(7420):393-396 Retrieved (https:// doi.org/10.1038/nature11493)

Huang J, Wang T, Wang W, Li Z, Yan H (2014) Climate effects of dustaerosols over East Asian arid andsemiarid regions. J Geophys Res, 119:11,398-11,416, https://doi.org/10.1002/2014JD021796

Igarashi Y, Irino T, Sawada K, Lu S, Furota S (2018) Fluctuations in the East Asian monsoon recorded by pollen assemblages in sediments from the Japan Sea off the southwestern coast of Hokkaido, Japan from 4.3 ma to the present. Glob Planet Chang 163:1-9 (https://doi.org/10.1016/j.gloplacha.2018.02.001)

Iglesias V, Whitlock C (2014) Fire responses to postglacial climate change and human impact in Northern Patagonia (41-43ㅇ). Proc Natl Acad Sci U S A 111(51):E5545-E5554 Retrieved (https://doi.org/10.1073/pnas.1410443111)

Irino T, Tada R (2003) High-resolution reconstruction of variation in Aeolian dust (Kosa) deposition at ODP site 797, the Japan Sea, during the last 200 Ka. Glob Planet Chang 35(1-2):143-156

Irino T, Tada R, Ikehara K, Sagawa T, Karasuda A, Kurokawa S, Seki A, Lu S (2018) Construction of perfectly continuous records of physical properties for darklight sediment sequences collected from the Japan Sea during Integrated Ocean Drilling Program Expedition 346 and their potential utilities as paleoceanographic studies. Prog Earth Planet Sci 5:23. https://doi.org/10. 1186/s40645-018-0176-7

Komarek EV Sr (1967) The nature of Lightning fires. Proc, Annual Tall Timbers Ecology Conference 7:5-41

Lisiecki LE, Raymo ME (2005) A Pliocene-Pleistocene stack of 57 globally distributed Benthic ?? 180 records. Paleoceanography 20(1):1-17

Marlon JR et al (2013) Global biomass burning: a synthesis and review of Holocene Paleofire records and their controls. Quat Sci Rev 65:5-25 Retrieved (http://dx.doi.org/10.1016/j.quascirev.2012.11.029)

Masiello C a (2004) New directions in black carbon organic geochemistry. Mar Chem 92(1-4):201-213

Masiello CA, Druffel ER (2001) Carbon isotope geochemistry of the Santa Clara River. Glob Biogeochem Cycles 15(2):407-416

Miyazaki Y et al (2007) Chemical characteristics of water-soluble organic carbon in the Asian outflow. Journal of Geophysical Research Atmospheres 112(22): $1-18$

Nie J et al (2008) Link between benthic oxygen isotopes and magnetic susceptibility in the red-clay sequence on the Chinese Loess Plateau. Geophys Res Lett 35(3):L03703 Retrieved (http:/ doi:10.1029/2007GL032817, 2008)
Novakov T (1984) The role of soot and primary oxidants in atmospheric chemistry. Sci Total Environ 36(C):1-10

Oshima N et al (2012) Wet removal of black carbon in Asian outflow: aerosol Radiative forcing in East Asia (A-FORCE) aircraft campaign. J Geophysical Res Atmospheres 117(3):1-24

Peters ME, Higuera PE (2007) Quantifying the source area of macroscopic charcoal with a particle dispersal model. Quat Res 67(2):304-310

Pokras EM, Mix AC (1987) Earth's precession cycle and quaternary climatic change in tropical Africa. Nature 326(6112):486-487 Retrieved September 29, 2017 (https://doi.org/10.1038/326486a0

Preston CM, Schmidt MWI (2006) Black (pyrogenic) carbon: a synthesis of current knowledge and uncertainties with special consideration of boreal regions. Biogeosciences 3(4):397-420

Schmidt MW, Skjemstad JO, Jäger C (2002) Carbon isotope geochemistry and nanomorphology of soil black carbon: black chernozemic soils in Central Europe originate from ancient biomass burning. Glob Biogeochem Cycles 16(4):70-1-70-78 Retrieved (https://doi.org/10.1029/2002GB001939)

Scott AC (2010) Charcoal recognition, taphonomy and uses in palaeoenvironmental analysis. Palaeogeogr Palaeoclimatol Palaeoecol 291(12):11-39 Retrieved (http://dx.doi.org/10.1016/j.palaeo.2009.12.012)

Sun X, Luo Y, Huang F, Tian J, Wang P (2003) Deep-sea pollen from the South China Sea: Pleistocene indicators of East Asian monsoon. Mar Geol 201(1-3): 97-118

Sun $Y$ et al (2006) East Asian monsoon variability over the last seven glacial cycles recorded by a loess sequence from the northwestern Chinese loess plateau. Geochem Geophys Geosyst 7(12):1-16

Swift RS (2001) Sequestration of carbon by soil. Soil Sci 166(11):858-871 Retrieved (https://journals.lww.com/soilsci/Fulltext/2001/11000/SEQUESTRATION_OF_ CARBON_BY_SOIL.10.aspx)

Tada R, Irino T, Ikehara K, Karasuda A, Sugisaki S, Xuan C, Sagawa T, Itaki T, Kubota Y, Lu S, Seki A, Murray RW, Alvarez-Zarikian C, Anderson WT Jr, Bassetti M-A, Brace BJ, Clemens SC, da Costa Gurgel MH, Dickens GR, Dunlea AG, Gallagher SJ, Giosan L, Henderson ACG, Holbourn AE, Kinsley CW, Lee G-S, Lee K-E, Lofi J, Lopes CICD, Saavedra Pellitero M, Peterson LC, Singh RK, Toucanne S, Wan S, Zheng H, Ziegler M (2018) High-resolution and -precision correlation of dark and light layers in the quaternary hemipelagic sediments of the Japan Sea recovered during IODP expedition 346. Prog Earth Planet Sci 5:19 DOI: 10.1186/s40645-018-0167-8

Tada R, Irino T, Koizumi I (1999) Land-ocean linkages over orbital and millennial timescales recorded in Late Quaternary sediments of the Japan Sea. Paleoceanography 14(2):236-247

Tada R et al. 2015. Expedition 346 Scientists (2015) Site U1423. 346, Proceedings of the Integrated Ocean Drilling Program, Volume 346 Retrieved (https://doi. org/10.2204/iodp.proc.346.104.2015).

Thevenon F et al (2010) Combining charcoal and elemental black carbon analysis in sedimentary archives: implications for past fire regimes, the pyrogenic carbon cycle, and the human-climate interactions. Glob Planet Chang 72(4): 381-389 Retrieved (http://dx.doi.org/10.1016/j.gloplacha.2010.01.014)

Verardo DJ, Ruddiman WF (1996) Late Pleistocene charcoal in tropical Atlantic Deep-Sea sediments: climate and geochemical significance. Geology 24(9): 855-857

Wang P (2003) Evolution of the South China Sea and monsoon history revealed in deep-sea records. Chin Sci Bull 48(23):2549,https://doi.org/10.1360/ $03 w d 0156$

Wang R et al (2012) Black carbon emissions in China from 1949 to 2050. Environ Sci Technol 46(14):7595-7603 Retrieved September 25, 2017 Retrieved (https://doi.org/10.1021/es3003684)

Yoon JH, Kim YJ (2009) Review on the seasonal variation of the surface circulation in the Japan/East Sea. J Mar Syst 78(2):226-236 Retrieved (http:// dx.doi.org/10.1016/j.jmarsys.2009.03.003)

Zhou B et al (2007) Elemental carbon record of Paleofire history on the Chinese loess plateau during the last $420 \mathrm{Ka}$ and its response to environmental and climate changes. Palaeogeogr Palaeoclimatol Palaeoecol 252(3-4):617-625 